\title{
A Rare Case Report of Ectopic Tooth in Submandibular Salivary Gland's Duct
}

\author{
Jabbar OA $A^{a}$, Mustafa $N S^{a}$, Kashmoola $M A^{a}$ \\ Kulliyyah of Dentistry, IIUM Kuantan Campus, Jalan Sultan Ahmad Shah, 25200 Kuantan, Pahang
}

\begin{abstract}
This case report highlights mandibular tooth in an ectopic position in the floor of the mouth, associated with submandibular salivary gland, which was completely obliterating the Wharton duct. Very few such cases have been reported in the literatures. Since ectopic tooth may lead to pain, discomfort sensation upon mastication, and even infection (sialadenitis), its diagnosis and treatment is essential.
\end{abstract}

KEYWORD: Ectopic tooth, submandibular duct, floor of mouth

\section{INTRODUCTION}

Tooth eruption is a multifaceted, localised and programmed process of development in which remodelling of the jaw bones occurs at an accurate timing. Eruptive process is a multistep event where interaction between the oral epithelium and the underlying mesenchymal tissue plays a vital role. Abnormal interaction at any step may result in ectopic tooth development and subsequent eruption. ${ }^{1}$

Ectopic eruption is the disturbance in which the tooth does not follow its usual course of eruption. Variety of problems can arise during the transitional dentition period and one such problem is ectopic eruption. Thus, early diagnosis can prevent a more complicated malocclusion. ${ }^{2}$

The presence of teeth extraorally has been reported in the ovaries, eyes, testes, anterior mediastinum, and presacral regions. In the oral and maxillofacial region, the presence of ectopic teeth has been reported in the maxillary sinus, chin, nose, mandibular condyle, coronoid process, and even the orbit. ${ }^{3}$

Corresponding Author

Asst. Prof. Dr. Omar Abdul Jabbar

Kulliyyah of Dentistry, IIUM Kuantan Campus, Jalan Sultan Ahmad Shah, Kuantan

Pahang. Malaysia

Tel No : +609-570 5504

Email : dromar@iium.edu.my
Within the dentate region, ectopic tooth is often seen in clinical practice, more commonly in the maxillary first permanent molars and canines, followed by mandibular canines, second premolars and maxillary lateral incisors; and it is found to be involved more common in females than males. While eruption in a non-dentate area such as in the floor of the mouth is very rare, eruption of mandibular canine in the floor of the mouth may precipitate complications or sometimes result in massive disturbance during activities of daily living. Ectopic condition may remain undiagnosed for many years until the patient accidentally undergoes radiographic examination for any reason and of unknown aetiology. ${ }^{5}$

Cheyne and Wessels reported an incidence of approximately 2 per cent in over 500 subjects studied at the State University of lowa, ${ }^{11}$ while Young' found this phenomenon in more than 3 per cent of her group of 1,619 white children living in the San Francisco Bayarea. ${ }^{12}$ Byrd found that more than one-third of his 444 subjects, five to ten years of age and living in North Carolina, had at least one example of ectopic eruption of a central incisor, lateral incisor, or first molar. ${ }^{13}$

Due to this rarity, we present a case of ectopic tooth in the floor of the mouth with its implication and management. 


\section{CASE REPORT}

A 34-year-old female Malay lady attended the polyclinic of Oral Pathology and Oral Medicine in Faculty of Dentistry, IIUM. She complained of pain with discomfort in the anterior area of the floor of the mouth upon mastication since 20 years ago.

The pain was mild and vague in its nature, accompanied by a sensation of sharp object close to the ventral surface of the tongue. During mouth movement, the patient presented a non-significant medical problem. On extra-oral examination, the patient was found to have a straight profile and symmetrical face. Intra-oral examination showed a round, pail hard swelling in the lower right side of the floor of the mouth with erythematous base, the size of which is about $0.5 \mathrm{~cm}$ by $1.0 \mathrm{~cm}$. The lesion is mobile and slightly tender on palpation in relation to the adjacent soft tissue of the floor of the mouth (Figure 1).

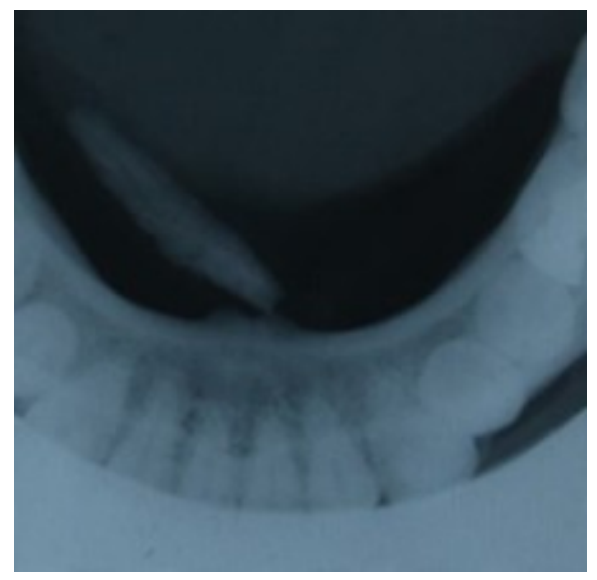

Figure 1

An intraoral occlusal radiograph was taken which revealed a radiopaque mass. It has a tooth like appearance and it's located on the anterior right side of the floor of the mouth, which was embedded superficially in horizontal orientation directly underneath the ventral surface of the tongue (Figure 2)

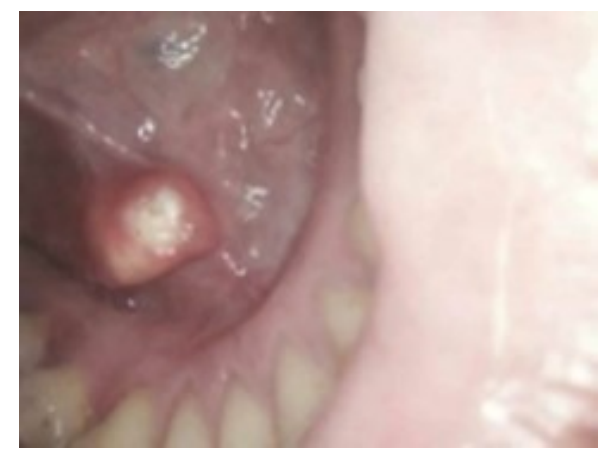

Figure 2
The clinical and radiographic appearance of the mass resembles a canine tooth structure with remarkable hypocalcification (Figure 3).

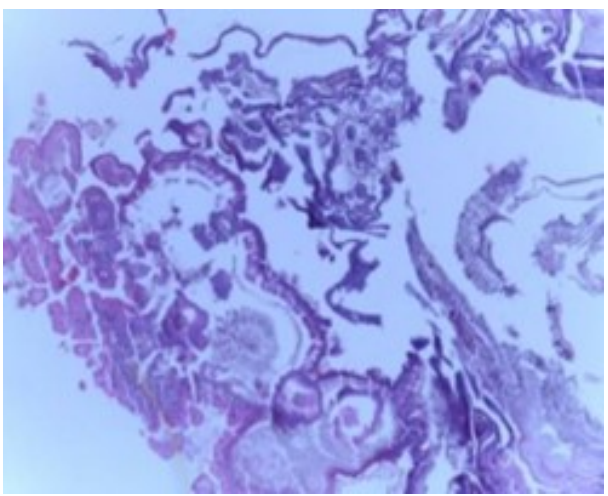

Figure 3

Histologically, hematoxylin and eosin sectioning of the calcified mass confirmed the presence of odontogenic tissue, dentin, pulp and cementum (Figure. 4)

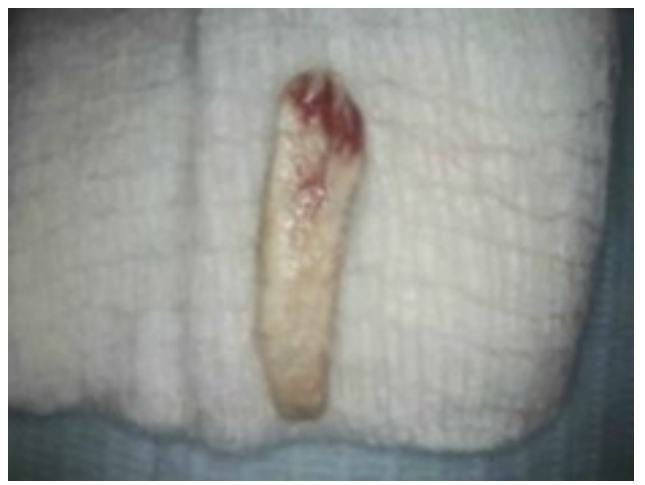

Figure 4

A signed consent form was taken from the patient, then local anesthesia was given to the right side mucosa of the floor of the mouth. Linear incision was done along the long axis of the tooth in order to expose the mass. The access was made using surgical blade $\# 15$, after that the tooth was removed by artery forceps and then the wound was sutured using 3.0 black silk suture.

A superficial incision was made preserving the orifice of the duct. Removal of the tooth was done, then superficial suturing including epithelium of the oral cavity and ductal structure was performed. The patient was called for review after 3 days, and revisit 6 days later. The stitches were removed during that visit. A good healing process was noticed over the operated area.

No further treatment or investigation was advised as the ectopic tooth was completely removed. After one month patient showed a total asymptomatic condition. 


\section{DISCUSSION}

Ectopic eruption of tooth is an extremely rare phenomenon. It refers to a tooth located away from the normal position in the vicinity of odontogenic structures. Another rare condition found in permanent dentition of unknown aetiology is transmigration of mandibular canine. ${ }^{6}$

The most common location for ectopic tooth eruption is the upper first permanent molar and canine followed by the mandibular canine and premolar. The aetiology of ectopic eruption is not completely understood and many theories had discussed it. Raghoebar with Nikiforuk suggests that the ectopic tooth is created from the arch growth deficiency. ${ }^{7}$ Another theory suggested that the disturbance in the balance between the rate of jaw growth with the rate of eruption of mandibular canine and/or size of the teeth would produce condition of ectopic eruption. $^{2}$

Kaya and Muzaffer in 2010 defined genetic predisposition as the causative factor of ectopic, ${ }^{8}$ but this is not constantly the cause. Ectopic eruption can be caused by deviations in jaw spaces that may be hereditary, as seen in micrognathia, but can also be acquired due to either early tooth extraction or delayed shedding of primary teeth. ${ }^{9}$

The intraductal ectopic tooth in the present case report is probably mandibular canine (supernumerary), because of its large sized, conical shaped crown with a single canalled root. Its eruption time was uncommonly late as the patient is 34 years-old. Furthermore, its root was completely formed with normal length.

On the basis of the clinical examination with its corresponded radiographic finding, ectopic tooth disclosed a roughened, pitted and irregular enamel. Thus, the more common scenario is would be enamel hypoplasia secondary to chronic obstructive sialadenitis, since our patient claimed of having a prolonged history of chronic pain accompanied with swelling especially at the meals time (meal syndrome).

In the current case, enamel hypoplasia involved ectopic tooth only, while the other remained teeth were shown to be normal, which is in agreement with the Rajendran study. Enamel hypoplasia is defined as a quantitative defect of enamel structure caused by a number of different factors producing injury to the ameloblasts, such as nutritional deficiencies, Rh hemolytic disease, exanthematous diseases, local trauma and inflammation. ${ }^{10}$

Hypoplastic enamel is visually and histomorphologically identified as an external defect involving the surface of the enamel and associated with reduced thickness of the enamel layer.

Taking into consideration the infrequent occurrence of ectopic tooth and its subsequent surgical removal, intraductal ectopic tooth of the mandible is extremely rare in the clinical practice and very few case have been reported in the literatures.

\section{CONCLUSION}

A case of an ectopic tooth intraductally placed within submandibular salivary gland of a_Malay lady was reported. This was one of the rarest documented case in the literatures. The patient also suffered from unilateral pain with considerable disturbed sensation during function. Early diagnosis and treatment of such tooth is important, because they have the potential to cause serious complication. The mandibular intraductal tooth may be under-reported in the literature.

\section{REFERENCES}

1. Rajesh R, Naveen V, Amit S, Baroudi K, Reddy CS, Namineni S, Case Report Treatment of Ectopic Mandibular Second Permanent Molar with Elastic Separators. Case Rep Dent. 2014; 11-4.

2. Yaseen SM, Naik S, Uloopi KS. Ectopic eruptionA review and case report. Contemp Clin Dent. 2011;2(1): 3-7.

3. Sateesh S Chavan VY. Mandible like structure with fourteen teeth in a benign cystic teratoma. Indian J Pathol Microbiol. 2009;52:595.

4. Torres-Lagares D, Flores-Ruiz R, Infante-Cossio P, Garcia-Calderon M, Gutierrez-Perez JL. Transmigration of impacted lower canine. Case 
report and review of literature. Oral Medicina, oral Pathology, Oral Surgery. 2006;11.

5. Hamed O. Al Dhafeeri, Abdulmajid Kavarodi, Khalil al Shaikh, Ahmed Bukhari, Omair Al Hussain, and Ahmed El Baramawy. Reccurent epistaxis caused by an intranasal supernumerary tooth in a young adult. Am J case Rep. 2014;15: 219-293.

6. Begtrup A, Gronasto H, Christensen IJ, Kjaer I. Predicting lower third molar eruption on panoramic radiographs. Eur J Orthod. 2013;35 (4): 460-6.

7. Raghoebar GM, Boering G, Vissink A, stegenga B. Eruption Disturbancesof Permanent Molars: a review. J Oral Pathol Med. 1991;20(4):159-66.

8. Kaya Gs, aslan M, Omezli MM, Dayi E. some morphological features related to mandibular third molar impaction. J clin Exp Dent. 2010;2 (1).

9. Artman L, Larsen HJ, Sorensen HB, Christensen IJ, Kjaer I. Differences between dentitions with palatally and labially located maxillary canines observed in incisor width, dental morphology and space conditions. Eur J Paediatr Dent. 2010;11(1): 82-6.

10. Brennan MT, textbook and color atlas of salivary gland pathology: Diagnosis and management. Head and Neck. 2012.

11. Cheyne V.D., and Wessels, K.E. Impaction of permanent First Molar with Resorption and space Loss in Region of Deciduous Second molar, J.A.D.A. 1947;35: 774.

12. Young, D.H. Ectopic of the First Permanent Teeth in Children between Five and Ten Years of Age. Unpublished Masters Thesis, University of North Carolina, 1954. 